\title{
A NEW SPECIES OF THE GENUS ADENISSUS LINNAVUORI, 1973 (HEMIPTERA: AUCHENORRHYNCHA: CALISCELIDAE) FROM CENTRAL IRAN, WITH A KEY TO SPECIES OF THE GENUS
}

\author{
VladimiR M. GNEZDilov \\ Zoological Institute, Russian Academy of Sciences \\ Universitetskaya Emb. 1, St. Petersburg 199034, Russia \\ E-mail:vmgnezdilov@mail.ru,vgnezdilov@zin.ru,https://orcid.org/0000-0002-7331-8744
}

Adenissus timokhovi sp. $\mathrm{n}$. is described after a male and female collected in Yazd Province of Iran. Key to species of the genus Adenissus Linnavuori is given and relationships of the species are discussed.

Key words: Ommatidiotinae, Adenissini, Adenissus, morphology, new species, Iran.

\section{INTRODUCTION}

The genus Adenissus Linnavuori, 1973 belongs, together with the genera Perissana Metcalf, 1952 and Raunolina Gnezdilov et Wilson, 2006, to the subtribe Adenissina Dlabola, 1980 of the tribe Adenissini Dlabola, 1980 (subfamily Ommatidiotinae Fieber, family Caliscelidae Amyot et Serville) (GNEzDilov 2013, 2017a). Adenissus was described by R. Linnavuori for a single species from southern Yemen (LinNavuori 1973). Soon after J. Dlabola enriched the genus by four species from southeastern Iran and one species from eastern Saudi Arabia (Dlabola 1980, 1985). Recently one more species was described from the United Arab Emirates (GnezdiLov 2017b). Thus currently the genus comprises 7 species, with 6 local endemics of Iran (south, southeast and east) and UAE, and one, Adenissus riadicus Dlabola, 1985, widely distributed in the Arabian Peninsula, where it is known from Saudi Arabia, United Arab Emirates, and Oman (GNezdilov et al. 2004, GNEZDilov \& WiLson 2006, 2011). Herewith I describe one more species from Central Iran (Yazd Province) rising the number of Iranian endemics to five and total number of species of the genus to eight.

\section{MATERIAL AND METHODS}

Morphological terminology follows Gnezdilov (2003) and Gnezdilov and Wilson (2011). The drawings were made using Leica MZ9.5 light microscope with camera lucida attached. The photos were taken using same microscope with camera Leica DFC 290. Images are produced using the software Helicon Focus and Adobe Photoshop.

Type specimens of the species described below are deposited in the Zoological Institute of the Russian Academy of Sciences, Saint Petersburg, Russia. 


\section{TAXONOMY}

Caliscelidae Amyot et Serville, 1843

Ommatidiotinae Fieber, 1875

Adenissini Dlabola, 1980

Adenissina Dlabola, 1980

\section{Genus Adenissus Linnavuori, 1973}

Adenissus Linnavuori, 1973: 125. Type species: Adenissus brachypterus Linnavuori, 1973.

Diagnosis. Metope wide, upper margin concave, sublateral carina are subparallel, not joined apically. Brachypterous. Fore wings with hypocostal plate, claval suture visible proximally. Hind margins of male pygofer with hook-shaped processes subapically. Suspensorium with awl-shaped process. Aedeagus without ventral hooks. Gonoplacs rounded, with dorso-caudal angles in lateral view not protruding above apex of anal tube.

\section{Key to species of Adenissus}

1 Coryphe slightly elongate, 1.5 times as wide between the eyes as long medially, with convex anterior margin. Rostrum long, reaching hind margin of abdominal sternite VII

- Coryphe transverse, 2-3 times as wide as long, with nearly straight, concave medially, anterior margin. Rostrum reaching only hind coxae 3

2 Fore wings reaching hind margin of tergite III. Yellow whitish in general coloration. Total length of female $6.3 \mathrm{~mm}$. Iran, Hormozgan Province

A. isinus Dlabola, 1980

- $\quad$ Fore wings reaching hind margin of tergite IV. Brown in general coloration. Total length of female $4.6 \mathrm{~mm}$. United Arab Emirates, Fujairah

A. fuscus Gnezdilov, 2017

3 Phallobase narrowing apically (in lateral view) (Fig. 9). Style with additional tooth (Figs 12, 13)

- Phallobase not narrowing apically (in lateral view). Style without additional tooth (GNezdilov \& Wilson 2011, figs 1, 6, 8, 13, 16, 19)

4 Processes of hind margins of pygofer weakly furcating apically. Male anal tube with deep apical notch (Dlabola 1980, fig. 29). Iran, Sistan va Baluchestan Province

A. baluchestanicus Dlabola, 1980 
- $\quad$ Processes of hind margins of pygofer horn-shaped, acute (Fig. 6). Male anal tube with apical concavity, sometimes weak (Fig. 8)

5 Style with apical and additional teeth, situated closely (Dlabola 1980, figs 11, 22)

- Style with apical and additional teeth, situated distantly (Figs 12, 13). Iran, Yazd Province A. timokhovi sp. n.

6 Male anal tube almost round, with very weak apical concavity (Dlabola 1980, fig. 20). Iran, Sistan va Baluchestan Province

A. zahedanicus Dlabola, 1980

- Male anal tube 1.5 times as long as wide medially, with distinct apical concavity (Dlabola 1980, fig. 10). Iran, Khorasan-e Jonoubi Province

A. zabolicus Dlabola, 1980

7 Fore wings reaching hind margin of tergite IV. Ventral phallobase lobe without collar subapically (GNezdilov \& Wilson 2011, fig. 17). Processes of hind margins of pygofer with truncate apices (GNezDILov \& Wilson 2011, fig. 18). Southern Yemen

A. brachypterus Linnavuori, 1973

- $\quad$ Fore wings reaching hind margin of tergites V-VI. Ventral phallobase lobe with collar subapically (Gnezdilov \& Wilson 2011, figs 3, 9). Processes of hind margins of pygofer with rounded apices (Gnezdilov \& Wilson 2011, figs 7, 12). Eastern Saudi Arabia, UAE, Oman

A. riadicus Dlabola, 1985

\section{Adenissus timokhovi sp. n.}

(Figs 1-13)

Type material. Holotype, male, Iran, Yazd Province, ca. $23 \mathrm{~km} \mathrm{SW}$ Kharanaq, $1600 \mathrm{~m}$, $32^{\circ} 11^{\prime} \mathrm{N} 54^{\circ} 30^{\prime}$ E, 31.V.2010, A. Timokhov leg. Paratype, female, Iran, Yazd Province, ca. 23

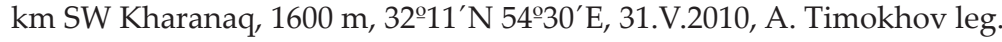

Description. Metope slightly elongate, lateral margins weakly convex, upper margin concave (Fig. 4). Sublateral carinae of metope running from its upper margin to metopoclypeal suture. Median carina of metope running from below its upper margin through postclypeus crossing metopoclypeal suture which is distinct. Coryphe transverse, twice as wide as long at midline, anterior margin 4-angled, weakly concave medially; posterior margin obtusely angulate (Figs 1,3). Pedicel elongately cylindrical (Fig. 4). Ocelli absent. Rostrum reaching hind coxae; 2nd and 3rd segments are almost equal in length; 3rd segment not narrowing apically. Pronotum slightly longer than coryphe, through concave in midline, with weak median carina; anterior margin strongly convex; posterior margin nearly straight. Paradiscal fields of pronotum very narrow behind the eyes. Paranotal lobes nearly square. Mesonotum with lateral carinae. Fore wings reaching hind margin of $\mathrm{V}$ tergite, straight truncated apically (Figs 1,3), with wide and long hypocostal plate running 
along whole wing margin (Fig. 2). Forewing sequence: R 2 M 1 CuA 1. CuP rudimentary, reaching only wing middle. Many transverse veins. Clavus as long as whole wing. Hind tibia with single lateral spine in its apical half and with 7 apical spines. First metatarsomere slightly longer than second one, with 2 latero-apical and 4 intermediate spines. Second metatarsomere with only 2 latero-apical spines. First and second metatarsomeres each with 7 long sclerotised basiconical dark brown setae on its ventral surface (Fig. 5). Arolium of pretarsus small. Claws twice longer than arolium (in dorsal view).

Coloration. Male. General coloration light yellow brownish (Figs 1, 2). Metope dark brown to black from its upper margin to the level of pedicel except light yellow carinae and traces of sensory pits. Coryphe with dark brown butterfly-shaped area medially and with dark brown stripes along lateral margins (Fig. 1). Postclypeus dark brown except its light upper part below metopoclypeal suture. Rostrum with black apex. Pedicell brown. Pronotum dark brown, with light yellow anterior and posterior margins, traces of sensory pits, and paradiscal fields. Paranotal lobes black, with light yellow margins and traces of sensory pits. Mesonotum dark brown between lateral carinae and median line. Fore wings with some cells darkened. Coxae, femora, and tibiae with black spots. Abdominal sternites and genital block light yellow. Abdominal tergites light yellow, with dark brown to black spots around traces of sensory pits. Third tarsomeres with dark brown apices. Claws black. Leg spines brown to dark brown.

Coloration. Female. Similar to male, except pronotum more light - light yellow in its middle part (Figs 3, 4). Abdominal sternites, anal tube, and pygofer light yellow. Abdominal tergites dark brown laterally. Apices of leg spines black.
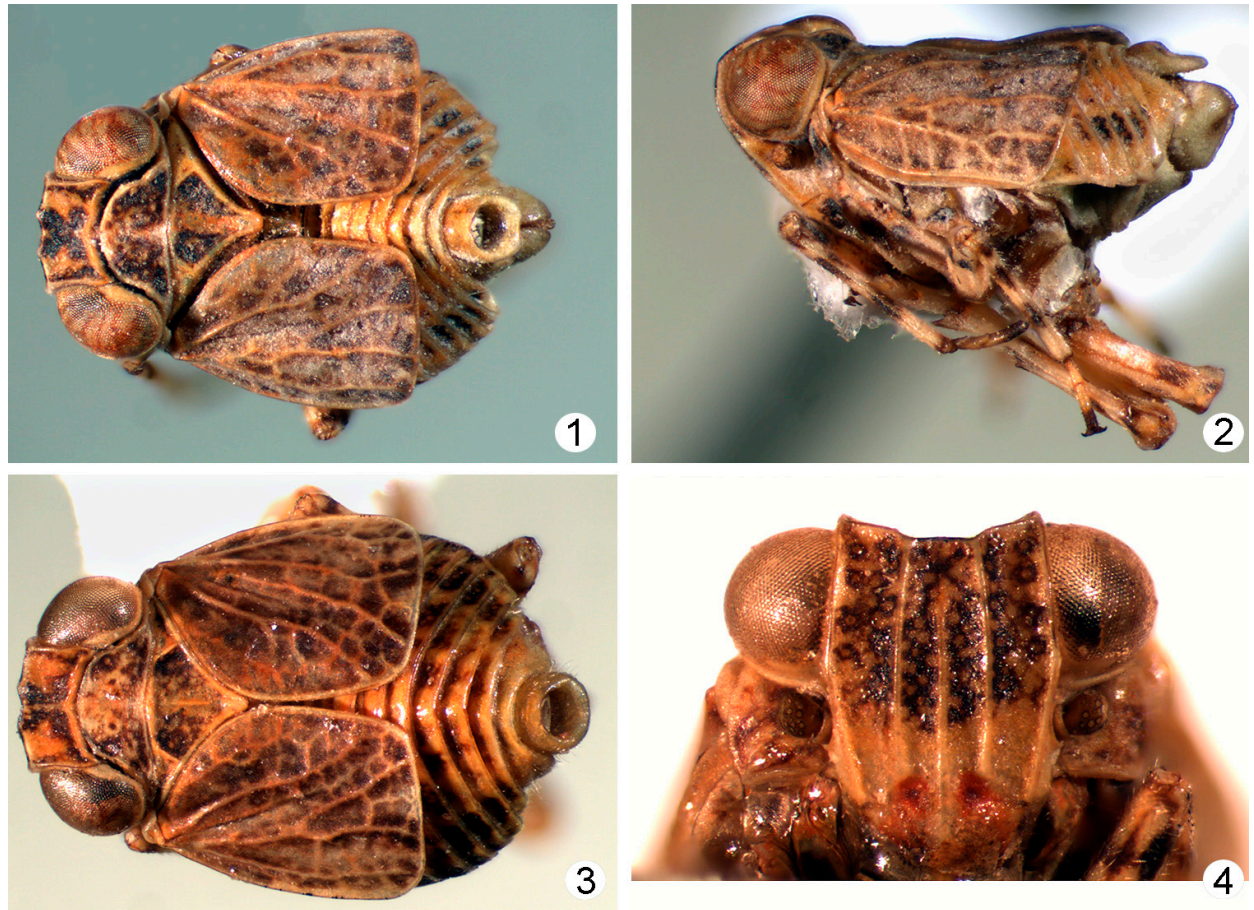

Figs 1-4. Adenissus timokhovi sp. n.: 1 = male, holotype, dorsal view; 2 = male, holotype, lateral view; 3 =female, paratype, dorsal view; 4 =female, paratype, frontal view 
Male genitalia (Figs 6-13). Hind margins of pygofer deeply concave, each with a big horn-shaped process in its upper third bearing deticles on its lower margin (Fig. 6). Anal tube wide, enlarged apically, with weak median concavity (in dorsal view) (Fig. 8). Suspensorium fused with phallobase, bearing awl-shaped process with denticated margins far not reaching phallobase apex (Figs 6, 9). Ventral margins of suspensorium process semiscircularly excavated below denticles. Phallobase long, narrowing apically (in lateral view), with two rows of denticles and with pair of swellings basally (Figs 9, 11). Phallobase with large phallotreme (Fig. 10). Connective large. Style large, with almost square plate; caudodorsal angle obtuse; hind margin convex (Fig. 6). Capitulum of style without neck, bearing apical tooth with denticles below (Fig. 7). Apical tooth of capitulum and additional tooth of style are widely separated (Figs 12,13).

Female genitalia. Anal tube wide, nearly rounded (in dorsal view).

Total length. Male $2.5 \mathrm{~mm}$, female $3.0 \mathrm{~mm}$.

Etymology. The species named after Russian hymenopterist Dr. Alexandr V. Timokhov (Moscow, Russia) who collected the type specimens.
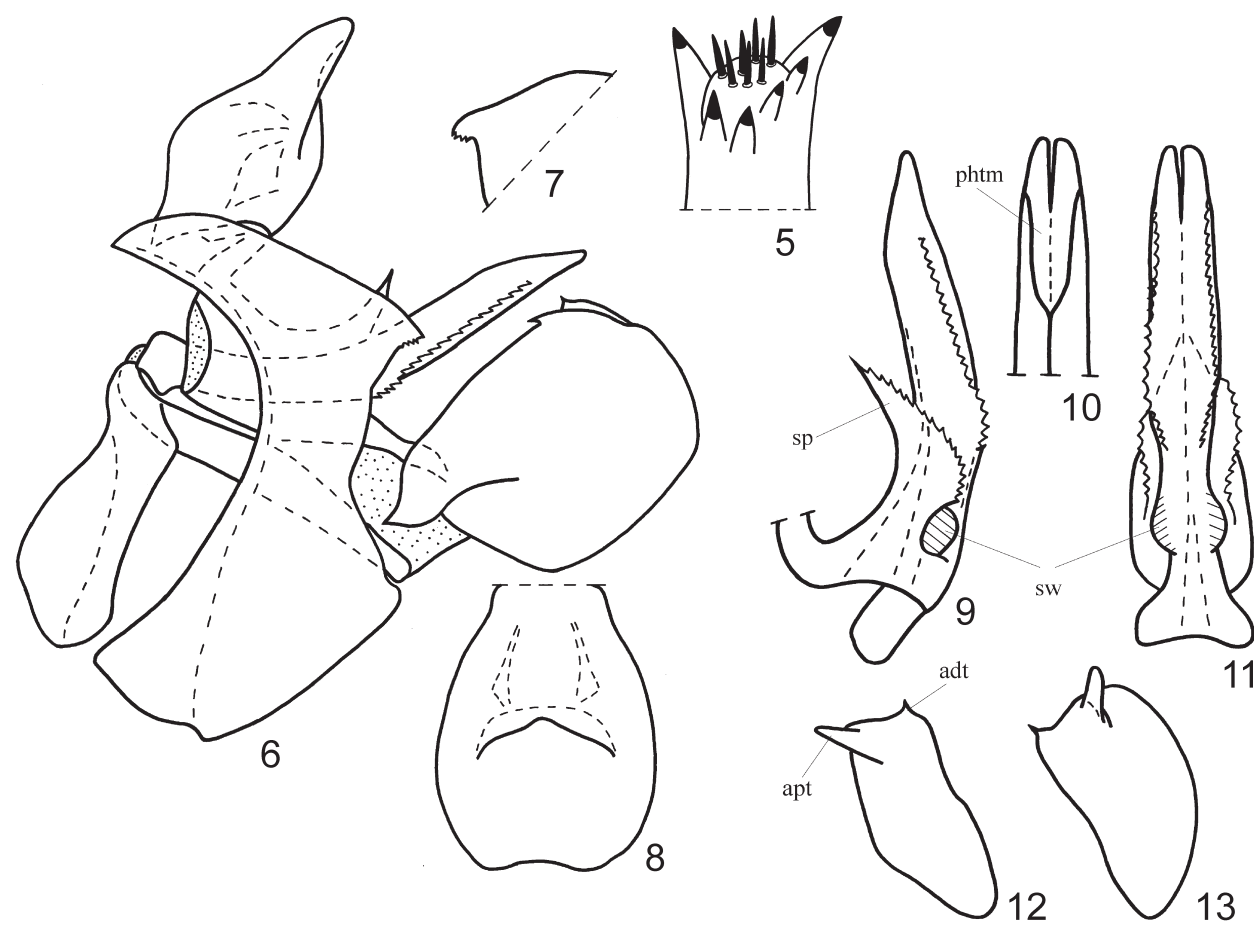

Figs 5-13. Adenissus timokhovi sp. n.: $5=$ female, paratype, first metatarsomere, ventral view; 6-13 = holotype, male genitalia: 6 = genital block, lateral view; 7 =capitulum of style, dorsolateral view; $8=$ anal tube, dorsal view, $9=$ phallobase with suspensorium, lateral view; $10=$ apex of phallobase, dorsal view; 11 = phallobase and suspensorium, ventral view; 12 = left style, dorsal view; 13 = right style, dorsal view. Abbreviations: $a p t=$ apical tooth; $a d t=$ additional tooth; $s p=$ process of suspensorium; $p h t m=$ phallotreme; $s w=$ swellings of phallobase 


\section{DISCUSSION}

Adenissus timokhovi sp. $\mathrm{n}$. well differs from all other species of the genus by its short awl-shaped process of suspensorium far not reaching phallobase apex (Fig. 9). In abris of hind margins pygofer and in shape of the processes of hind margins (Fig. 6) as well as in shape of aedeagus with slightly curved apex (Fig. 9) A. timokhovi sp. n. is closely related to A. zabolicus Dlabola, 1980 known from Khorasan-e Jonoubi Province of Iran at the eastern part of the country (Dlabola 1980, figs 8, 14). However, the new species is well distinguished by its peculiar style with widely separated teeth (Figs 12, 13) and smaller size of specimens.

Within the genus Adenissus there are two groups of species according to the structure of male genitalia. One group includes $A$. brachypterus and $A$. riadicus from the Arabian Peninsula with wide phallobase and style without any additional tooth. Another group includes Iranian species with narrow phallobase and style with additional tooth. A. fuscus Gnezdilov, 2017 occupies intermediate position as it has wide phallobase close to the Arabian species, but has the style with small rounded additional tooth. A. isinus Dlabola, 1980 is closely related to $A$. fuscus according to external morphological characters (GNEZDILOv 2017b), but its male is still unknown. Iran is probably a centre of diversification of this desert caliscelid genus and from this territory the genus distributed to the Arabian Peninsula, however, further molecular studies are needed to confirm this hypothesis.

Acknowledgements - I thank Dr. Dmitry Yu. Tishechkin (Moscow, Russia) who provided the material for my study which was performed in the framework of the Russian State Research project № AAAA-A19-119020690101-6.

\section{REFERENCES}

Dlabola, J. (1980): Tribus - Einteilung, neue Gattungen und Arten der subf. Issinae in der eremischen zone (Homoptera, Auchenorrhyncha). - Acta Musei Nationalis Pragae 36B: 173-247.

Dlabola, J. (1985): Neue mediterrane, eremische und ostafrikanische Issiden-Taxone (Hom., Auchenorrhyncha). - Sborník Národního Muzea v Praze, Řada B, Př́rodní Vědy 40: 217-243.

Gnezdilov, V. M. (2003): Review of the family Issidae (Homoptera, Cicadina) of the European fauna, with notes on the structure of ovipositor in planthoppers. - Chteniya pamyati N.A. Kholodkovskogo (Meetings in memory of N.A. Cholodkovsky), St. Petersburg 56(1): 1- 145. [In Russian with English summary] 
Gnezdilov, V. M. (2013): Modern system of the family Caliscelidae Amyot et Serville (Homoptera, Fulgoroidea). - Zoologichesky Zhurnal 92(10): 1309-1311. [in Russian] [English translation published in Entomological Review 2014, 94(2): 211-214.] https:// doi.org/10.1134/S0013873814020092

GnezDilov, V. M. (2017a): First record of the genus Raunolina (Hemiptera: Fulgoroidea: Caliscelidae) from tropical Africa with description of two new species from Sudan and Saudi Arabia. - Acta Entomologica Musei Nationalis Pragae 57(1): 11-22. https://doi. org/10.1515/aemnp-2017-0054

GNEZDilov, V. M. (2017b): A new species of the genus Adenissus (Hemiptera, Fulgoroidea, Caliscelidae) from United Arab Emirates. - Proceedings of the Zoological Institute RAS 321(3): 320-325.

Gnezdilov, V. M., Drosopoulos, S. \& Wilson, M. R. (2004): New data on taxonomy and distribution of some Fulgoroidea (Homoptera, Cicadina). - Zoosystematica Rossica 12(2): 217-223.

Gnezdilov, V. M. \& Wilson, M. R. (2006): Systematic notes on tribes in the family Caliscelidae (Hemiptera: Fulgoroidea) with the description of new taxa from Palaearctic and Oriental Regions. - Zootaxa 1359: 1-30. https://doi.org/10.11646/zootaxa.1359.1.1

Gnezdilov, V. M. \& Wilson, M. R. (2011): Order Hemiptera, family Caliscelidae. - Arthropod fauna of the UAE 4: 114-122.

Linnavuori, R. (1973): Hemiptera of the Sudan, with remarks on some species of the adjacent countries 2. Homoptera Auchenorrhyncha: Cicadidae, Cercopidae, Machaerotidae, Membracidae and Fulgoroidea. (Zoological contribution from the Finnish expeditions to the Sudan no. 33). - Notulae Entomologicae 53: 65-137.

Received September 13, 2019, accepted November 12, 2019, published May 15, 2020 
